(2)

OPEN ACCESS

\title{
Novel steroid infiltration technique of the carpal tunnel
}

\author{
Nauar Knightly, ${ }^{1}$ Laura Finnegan, ${ }^{1}$ Tayyab Qayyum, ${ }^{1}$ Jack L Kelly ${ }^{2}$
}

'Plastic and Reconstructive Surgery, Galway University Hospitals, Galway, Ireland ${ }^{2}$ Department of Plastic Surgery, Galway University Hospitals, Galway, Ireland

\section{Correspondence to} Dr Nauar Knightly; nauar.knightly@gmail.com

Accepted 6 April 2021
D Check for updates

(c) BMJ Publishing Group Limited 2021. Re-use permitted under CC BY-NC. No commercial re-use. See rights and permissions. Published by BMJ.

\begin{tabular}{|l|}
\hline To cite: Knightly N, \\
Finnegan L, Qayyum T, \\
et al. BMJ Case Rep \\
2021;14:e240764. \\
doi:10.1136/bcr-2020- \\
240764 \\
\hline
\end{tabular}

\section{SUMMARY}

This report describes a novel technique of steroid infiltration of the wrist to treat symptomatic carpal tunnel syndrome. Our approach potentially reduces direct trauma to the median nerve when compared with current conventional techniques. The use of a cannula allows infiltration directly into the carpal tunnel and advancement of the blunt tip minimises the risk of sharp trauma to the median nerve and adjacent tendons. This avoids the unpleasant, shooting pain frequently experienced by patients using traditional needle infiltration. We anticipate this would be of particular benefit in reducing pain associated with the procedure.

\section{BACKGROUND}

Carpal tunnel syndrome is the most common nerve entrapment syndrome of the upper limb and is often diagnosed using nerve conduction studies and ultrasound. ${ }^{1}$ The nerve may be swollen in the proximal carpal tunnel and is susceptible to injury during needle infiltration. A number of papers have attempted to protect the nerve by describing particular anatomical landmarks during needle infiltration and anatomical variations of the median nerve. $^{23}$

\section{CASE PRESENTATION}

A 54-year-old right hand dominant woman was referred to our services by haematology colleagues with long-standing paraesthesia in her right hand and nerve conduction study-proven severe carpal tunnel syndrome. The patient was taking warfarin (international normalised ratio (INR) 3.2) due to a history of subclavian vein thrombosis in the symptomatic limb. No other relevant medical history was noted. She described symptoms of pain and paraesthesiae along the distribution of the median nerve. The patient was reluctant to consider surgery given her history of thrombosis and requested a trial of steroid injection directly into the carpal tunnel. Direct needle infiltration can involve pain and with the high INR, there was also an associated risk of bleeding. We discussed the use of a blunt-tipped cannula to directly infiltrate the carpal tunnel with steroid and the patient agreed.

The median nerve was located by strongly flexing the fingers and thumb (video 1). This manoeuvre allows the median nerve to be identified by rolling it in an ulnar to radial direction. A small blister of local anaesthetic was infiltrated into the volar aspect of the wrist over the proximal wrist crease (video 2; figure 1). A small nick in the skin directly ulnar to the median nerve (figure 2) allows the cannula to pass underneath the transverse carpal ligament (TCL) and parallel to the nerve and into the carpal tunnel (figure 3). The cannula is passed at a $45^{\circ}$ angle underneath the TCL and then the angle is further reduced to prevent contact with the median nerve as the cannula is fed distally (video 3). Therefore, blunt piercing of the TCL does not take place but rather the antebrachial fascia of the forearm. Prior to infiltration, the cannula tip should be at its most distal position (figure 4). The steroid is slowly infiltrated (10 mg of triamcinolone) into the tunnel and the cannula is withdrawn proximally while infiltrating. The technique is approachable, even with a slight learning curve to it. It can be taught to trainees and most importantly it is comfortable for the patient. The trajectory and length of the cannula is illustrated in figure 5 .

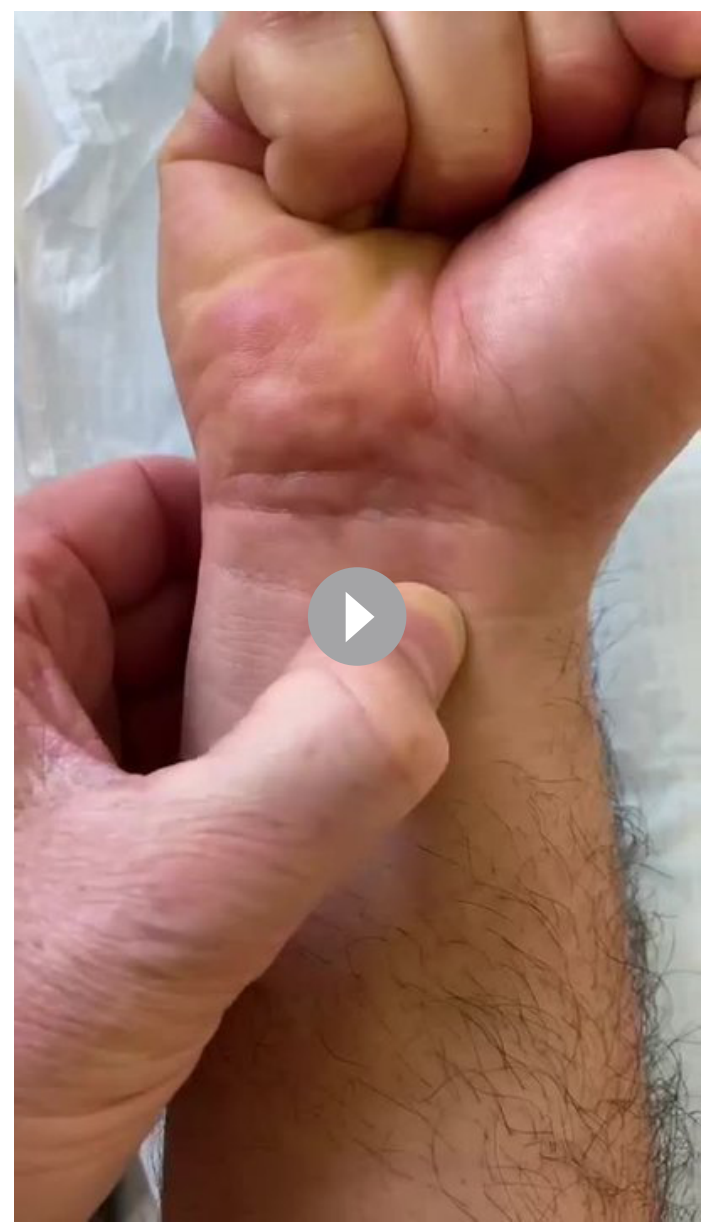

Video 1 Palpation of the median nerve. The wrist is palpated to locate the median nerve prior to continuing with the procedure. 


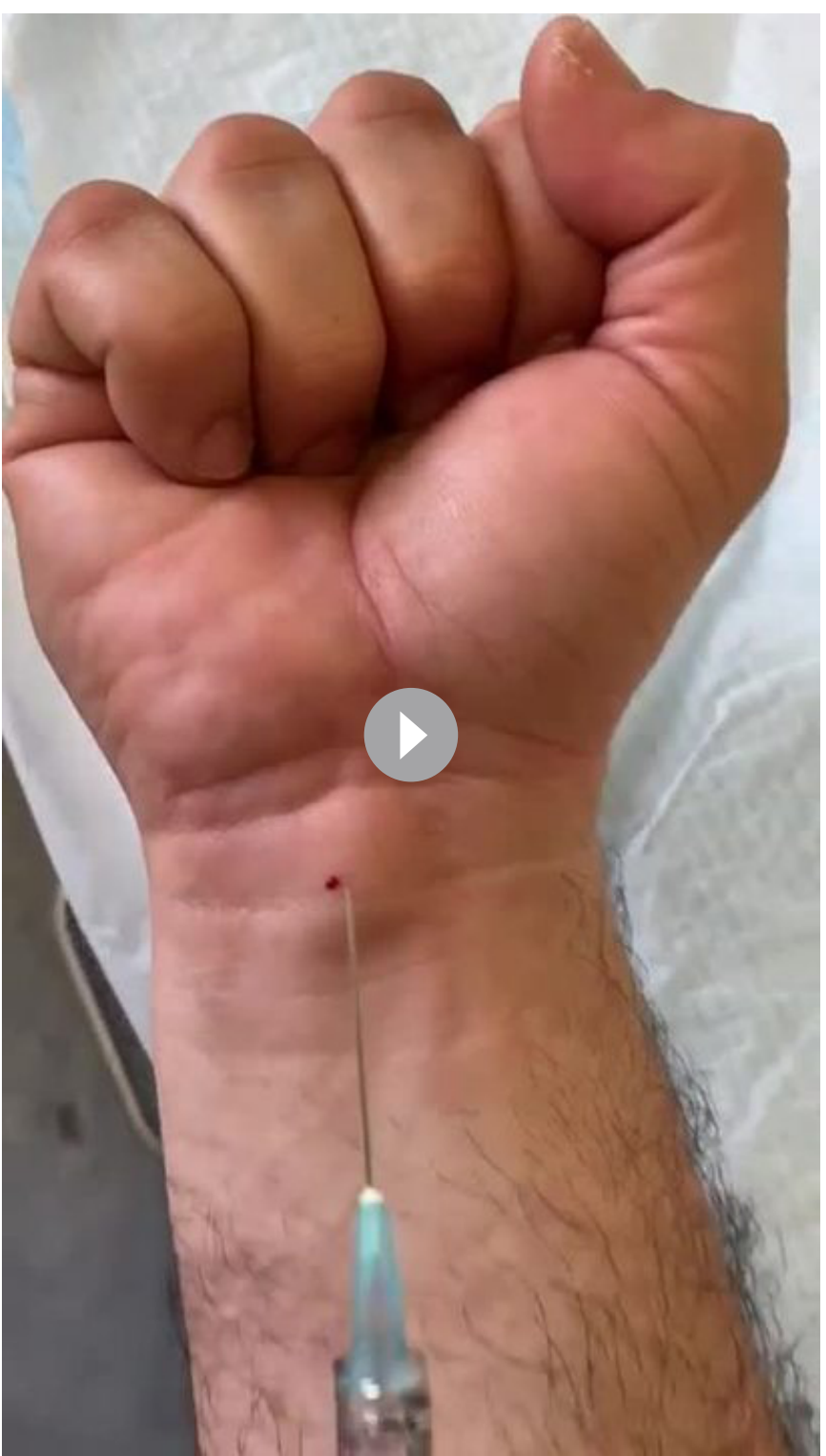

Video 2 Anaesthetic bleb injected. A small blister of anaesthetic is injected into the skin to prevent any pain during the blunt injection.

\section{TREATMENT}

The treatment options for carpal tunnel are well established and defined. They include splinting, steroid injection and surgery (open and endoscopic). Splinting is considered a temporary option before more definitive measures are considered. ${ }^{4}$ It is particularly useful for reversible causes of carpal tunnel syndrome, such as pregnancy. The effectiveness of each treatment option is variable but all modalities have proven efficacy in various published meta-analyses. ${ }^{4-6}$ The definitive treatment is surgical release of the carpal tunnel. However, atraumatic infiltration techniques are not frequently taught/described. Treatments should be approached cautiously and without trauma, where possible, especially in cases with a high INR, such as is the case in this patient.

\section{OUTCOME AND FOLLOW-UP}

The patient was followed up in the outpatient clinic 4 weeks post-injection. She was symptom free and would be interested in undergoing the same procedure again if she was to become symptomatic. She was followed up 3 months post-injection in

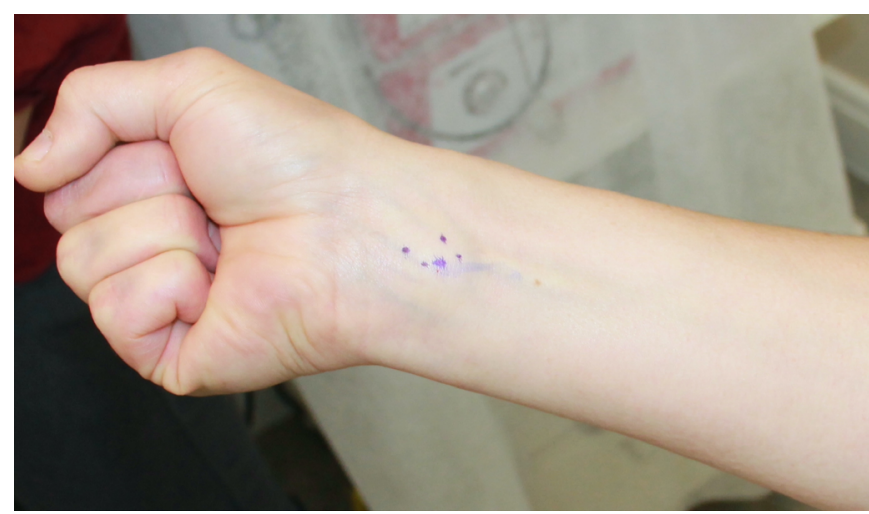

Figure 1 Marking of the median nerve and application of a blister of anaesthetic. The trajectory of the median nerve is marked out and a bleb of local anaesthetic is applied to the site of entry.

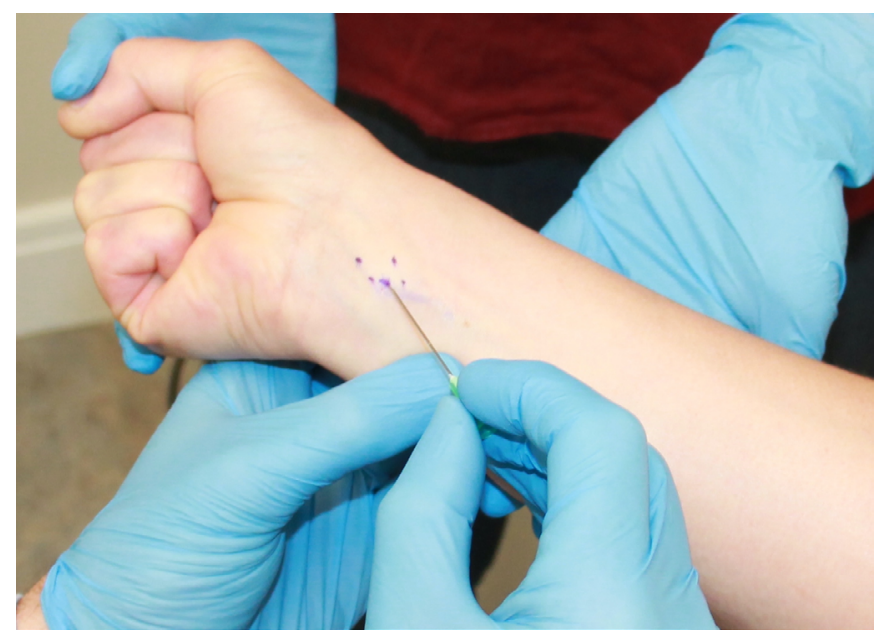

Figure 2 Access for the blunt cannula is made. A small nick is made in the skin to facilitate advancement of the blunt cannula.

the outpatient department and was still symptom free. She is aware that the definitive treatment is surgical release but wishes to delay or avoid this where possible due to her risk of bleeding. She has been counselled that surgical release may be required if the symptoms reoccur after two steroid injections.

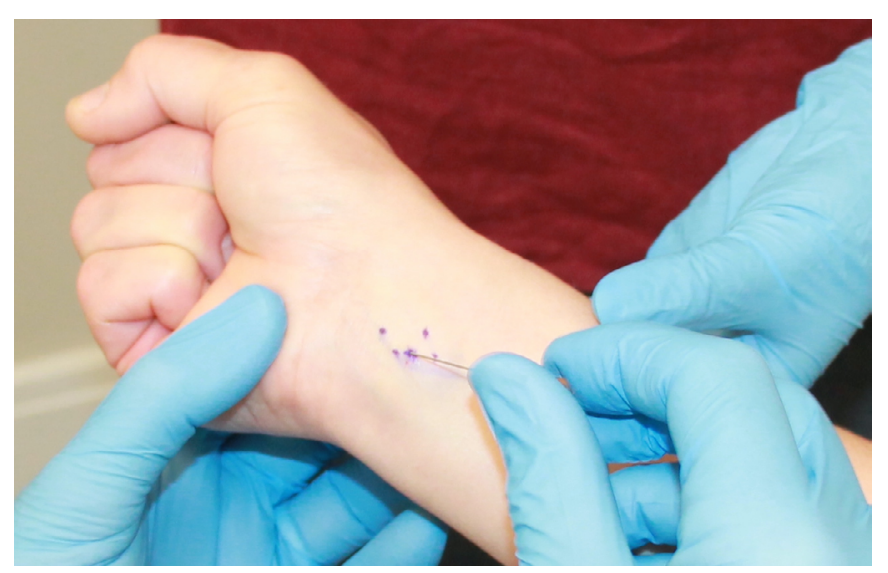

Figure 3 Blunt cannula tip advanced. The blunt cannula tip is advanced at $45^{\circ}$ to enter the carpal tunnel under the transverse carpal ligament. 


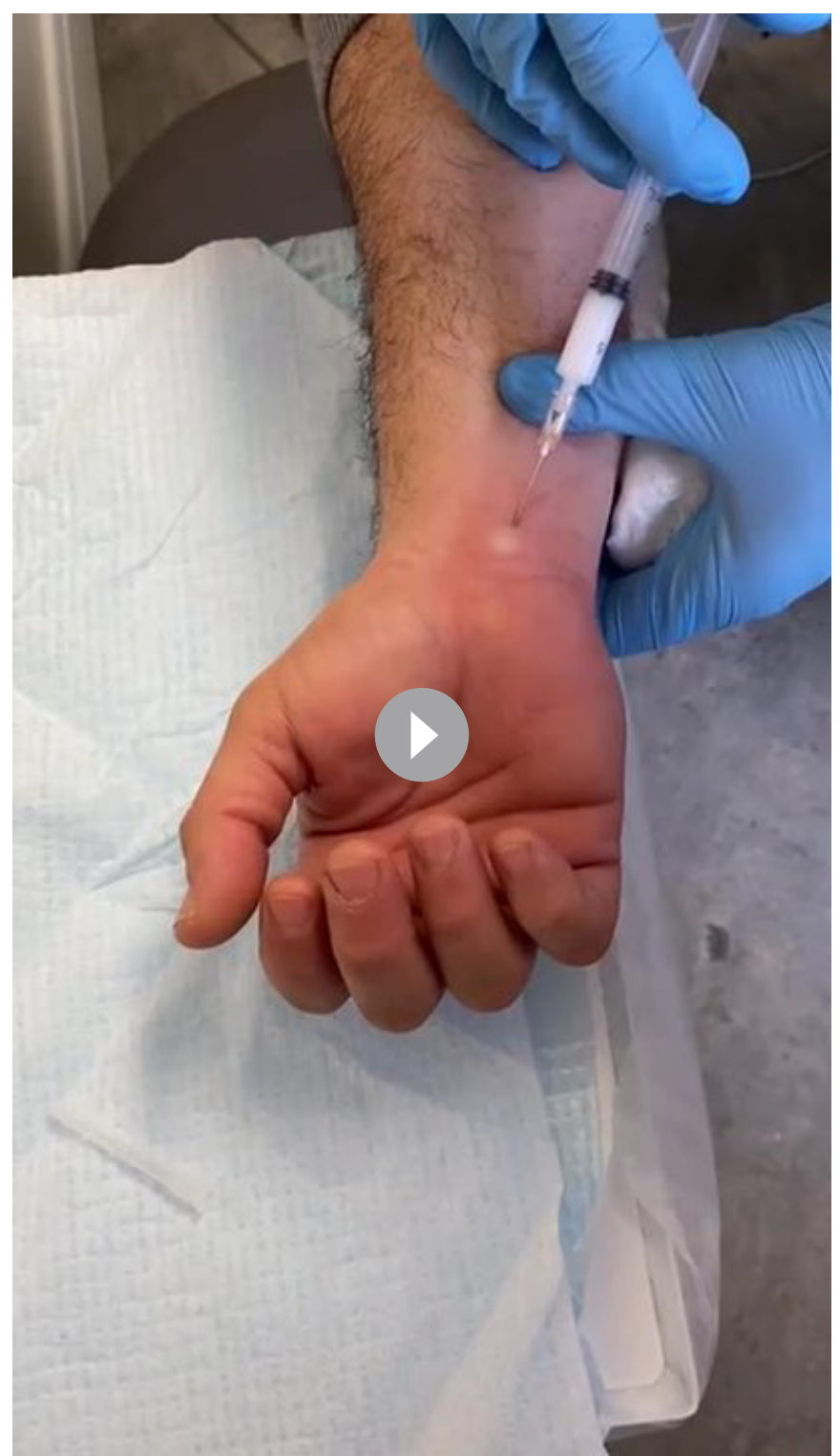

Video 3 Blunt injection. The blunt cannula is fed through the anaesthetic injection site and slowly pushed through the antebrachial fascia, underneath the transverse carpal ligament. There is a noticeable give when the carpal tunnel is entered. The steroid solution is then injected.

\section{DISCUSSION}

Carpal tunnel syndrome is a common condition with an annual incidence of 99/100 000, and a slight female predilection. ${ }^{7}$ Recent reports recommend first-line management options such as a trial of splinting or steroid injection directly into the carpal tunnel. Variable techniques such as distal and proximal carpal tunnel infiltration have been considered. A number of anatomical cadaveric studies have attempted to locate the median nerve within the wrist in order to minimise direct trauma to the nerve and adjacent structures. Most practitioners will report occasional difficulty when injecting the wrist with steroid and many will confess to having caused sudden pain by injecting directly into the median nerve.

Ultrasonic localisation nerve prior to infiltration has also been used to identify anatomical variations and swelling within the nerve in the proximal carpal tunnel. The National Institute for Health and Care Excellence and Royal College of Surgeons

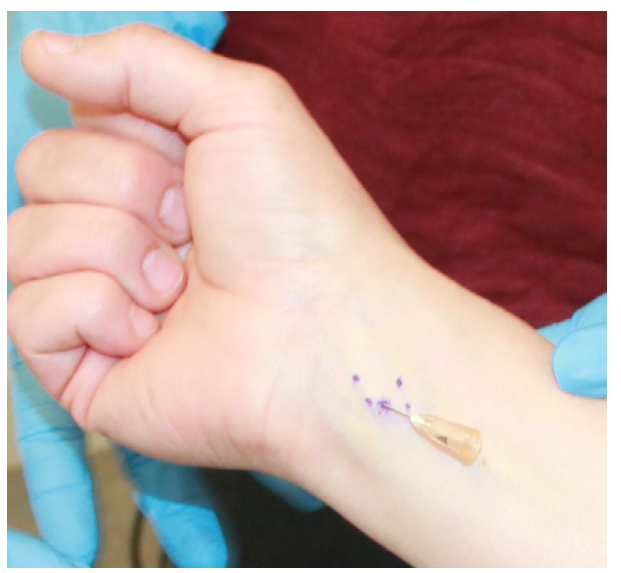

Figure 4 Cannula in carpal tunnel. The blunt tip cannula in situ, lying parallel to the median nerve in the carpal tunnel. The cannula is advanced distally prior to infiltration. As the tunnel is being infiltrated, the cannula is slowly and simultaneously withdrawn to achieve proximal as well as distal infiltration.

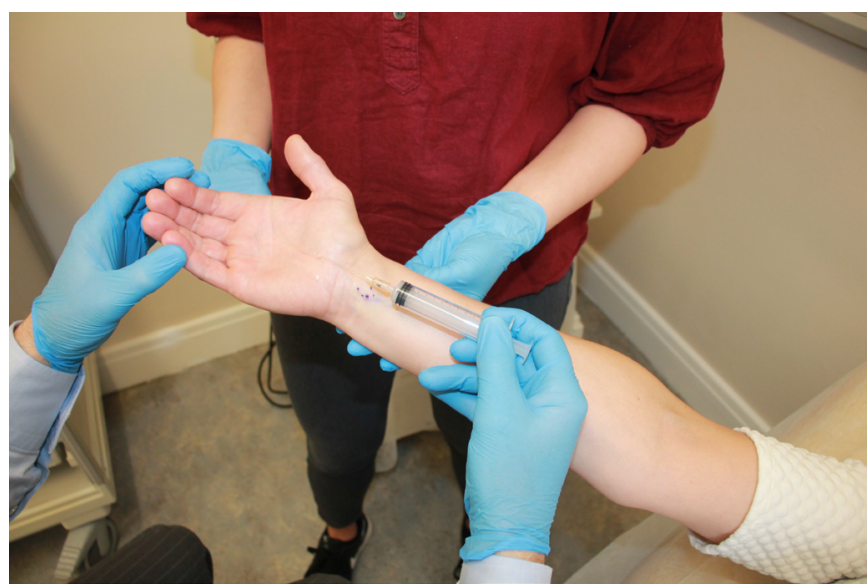

Figure 5 Trajectory of injection. Image illustrating the cannula length and trajectory while lying within the carpal tunnel.

guidelines ${ }^{8}$ recommend splinting at night and a single corticosteroid injection for initial management in the primary care setting. Further management with corticosteroids is not recommended as it may delay surgical decompression. Corticosteroid infiltration is an appropriate treatment modality for high-risk patients (as in our case) and for patients who wish to avoid surgical intervention. Any functional impairment as a result of carpal tunnel syndrome should be managed by a specialist.

We describe a novel technique that allows localisation of the median nerve and infiltration using a blunt cannula to minimise

\section{Patient's perspective}

I was very happy to have the injection done. I know I'm a slightly higher risk patient due to my blood thinning medication and I'm not comfortable with the thought of surgery. I got good relief from the pins and needles and pain in the hands. It used to cause me pain at night and even since the injection my hands are great. It was painless to go through. If it happens to me again I want to have the same treatment again as surgery is not something I want unless I have no other option. 


\section{Learning points}

Carpal tunnel infiltration can be performed with this novel technique.

- The safety and efficacy profile of this is still being established with case series which are being gathered.

- The potential benefit of this technique is infiltration of the carpal tunnel without traumatising the median nerve and causing shooting pain and discomfort to the patient.

- In high-risk patients on anticoagulation, steroid infiltration with atraumatic approach may be the most prudent approach.

direct trauma to the nerve itself and adjacent structures. To our knowledge, no other case report or study has described this method of carpal tunnel infiltration.

Contributors NK wrote the case report. JLK developed the technique and supplied photo documentation as well as revision of the article. TQ did patient follow-up in clinic and documentation of clinical status. LF did background reading and references on the subject.

Funding The authors have not declared a specific grant for this research from any funding agency in the public, commercial or not-for-profit sectors.
Competing interests None declared.

Patient consent for publication Obtained.

Provenance and peer review Not commissioned; externally peer reviewed.

Open access This is an open access article distributed in accordance with the Creative Commons Attribution Non Commercial (CC BY-NC 4.0) license, which permits others to distribute, remix, adapt, build upon this work non-commercially, and license their derivative works on different terms, provided the original work is properly cited and the use is non-commercial. See: http://creativecommons.org/ licenses/by-nc/4.0/.

\section{REFERENCES}

1 Yoshii Y, Zhao C, Amadio PC. Recent advances in ultrasound diagnosis of carpal tunnel syndrome. Diagnostics 2020;10. doi:10.3390/diagnostics10080596. [Epub ahead of print: 15 Aug 2020].

2 Brooks R, Kistler A, Chowdhry S, et al. Anatomic landmarks to locate the median nerve for safe wrist block or carpal tunnel steroid injection. Eplasty 2019;19:e19.

3 Henry BM, Zwinczewska H, Roy J, et al. The prevalence of anatomical variations of the median nerve in the carpal tunnel: a systematic review and meta-analysis. PLoS One 2015;10:e0136477.

4 Page MJet al. Splinting for carpal tunnel syndrome. Cochrane Database Syst Rev 2012.

5 Marshall SC, Tardif G, Ashworth NL, et al. Local corticosteroid injection for carpal tunnel syndrome. Cochrane Database Syst Rev 2007:29.

6 Scholten RJPM, Mink van der Molen A, Uitdehaag BMJ, et al. Surgical treatment options for carpal tunnel syndrome. Cochrane Database Syst Rev 2007;17.

7 Schwartz RH, Urits I, Viswanath O. Carpal tunnel injection, in StatPearls. Treasure Island (FL: StatPearls Publishing Copyright @ 2020, StatPearls Publishing LLC, 2020.

8 (Eng), R.C.o.S. Commissioning guide: treatment of carpal tunnel syndrome. National Institute for Health and Care Excellence, 2017.

Copyright 2021 BMJ Publishing Group. All rights reserved. For permission to reuse any of this content visit https://www.bmj.com/company/products-services/rights-and-licensing/permissions/

BMJ Case Report Fellows may re-use this article for personal use and teaching without any further permission.

Become a Fellow of BMJ Case Reports today and you can:

- Submit as many cases as you like

- Enjoy fast sympathetic peer review and rapid publication of accepted articles

- Access all the published articles

- Re-use any of the published material for personal use and teaching without further permission

Customer Service

If you have any further queries about your subscription, please contact our customer services team on +44 (0) 2071111105 or via email at support@bmj.com.

Visit casereports.bmj.com for more articles like this and to become a Fellow 